\title{
Therapeutic effect of epidural hyaluronic acid in a rat model of foraminal stenosis
}

\author{
Francis Sahngun Nahm' \\ Pyung Bok Lee' \\ Ghee Young Choe ${ }^{2}$ \\ Young Jin $\mathrm{Lim}^{3}$ \\ Yong Chul Kim ${ }^{3}$ \\ 'Department of Anesthesiology \\ and Pain Medicine, ${ }^{2}$ Department of \\ Pathology, Seoul National University \\ Bundang Hospital, Seongnam-si, \\ ${ }^{3}$ Department of Anesthesiology \\ and Pain Medicine, Seoul National \\ University Hospital, Seoul, Republic \\ of Korea
}

Correspondence: Pyung Bok Lee Department of Anesthesiology and Pain Medicine, Seoul National University Bundang Hospital, Gumi-dong 300, Bundang-gu, Seongnam-si, I3620,

Republic of Korea

Tel +82 3I 7877499

Fax +82317874063

Email painfree@snubh.org
This article was published in the following Dove Press journal:

Journal of Pain Research

25 January 2017

Number of times this article has been viewed

Purpose: Since receiving a warning from the US Food and Drug Administration (FDA) about injection of corticosteroids into the epidural space having serious adverse events, we have sought alternative medications for injection at this site. Hyaluronic acid (HA) has anti-adhesive, anti-inflammatory, and lubricating properties, so could potentially be useful for spinal pain. The exact mechanism by which spinal stenosis develops is not fully understood, but is likely to involve inflammation. Therefore, we hypothesized that HA could have a therapeutic effect in spinal stenosis. This study evaluated the effects of epidural administration of HA on alleviation of pain in a rat model of foraminal stenosis.

Materials and methods: After creating the animal model, HA (HA group) or saline solution (S group) was administered via an epidural catheter. The paw-withdrawal threshold to mechanical stimulation and motor dysfunction were monitored for up to 21 days. Tissue was collected to evaluate the degree of adhesion, inflammation in the perineural area, and chromatolysis in the dorsal root ganglion (DRG).

Results: The mechanical withdrawal threshold was restored in the HA group but not in the $\mathrm{S}$ group $(P<0.001)$. The HA group also showed less fibrosis $(P=0.026)$ and less chromatolysis $(P=0.002)$ than the $\mathrm{S}$ group.

Conclusion: HA administered epidurally had a therapeutic effect on the allodynia and hyperalgesia induced by chronic compression of the DRG.

Keywords: adhesion, epidural, fibrosis, hyaluronic acid, inflammation, spinal stenosis, pain

\section{Introduction}

Epidural steroid injections have been used to treat spinal pain worldwide for several decades. ${ }^{1-3}$ However, the US Food and Drug Administration (FDA) issued a letter in 2014 warning that epidural corticosteroid injections used to control spinal pain may result in serious complications. ${ }^{4}$ The FDA also stated that the effectiveness and safety of epidural corticosteroid injections have not been established and that this treatment is not approved for use in the treatment of spinal pain. The debate concerning epidural steroid therapy is ongoing, and an expert panel could not reach agreement on the subject. ${ }^{5}$ Against this background, we have been seeking alternative medications for epidural use when attempting to reduce spinal pain and have become interested in the characteristics of hyaluronic acid (HA). HA is a carbohydrate polymer distributed widely in the connective and neural tissue and has many clinical applications, including intra-articular injection, ${ }^{6,7}$ soft tissue augmentation, ${ }^{8}$ wound healing, ${ }^{9}$ and prevention of adhesions after surgery, ${ }^{10}$ because of its anti-inflammatory, lubricating, and antiadhesive properties. Moreover, HA is known to inhibit proliferation of macrophages 
and release of cytokines ${ }^{11}$ and has been suggested to promote nerve regeneration. ${ }^{12}$ Epidural adhesions are one of the major concerns after spinal surgery, and many treatment methods have been used to attenuate epidural adhesions related to spinal surgery. ${ }^{13,14}$ Because of its beneficial effects and ease of application, HA has attracted interest as an agent that could reduce epidural fibrosis after spinal surgery. Previous studies of the mechanism of action of HA in spinal pain have been performed mainly in the postoperative period. ${ }^{15-17}$ However, there have been no studies on the effect of HA on spinal stenosis. Recently, there has been a report on increased concentrations of HA in cerebrospinal fluid (CSF), especially in patients with spinal disorders. ${ }^{18}$ The increased HA concentrations in CSF are thought to be an essential component in the protection of cells and tissues in the spinal cord, and HA is suggested to play a role in the repair of tissues affected by mechanical stress or inflammation. ${ }^{18}$

We hypothesized that the anti-inflammatory and antiadhesive effects of HA could have a therapeutic effect on spinal pain with causes other than surgery, for example, spinal stenosis. The purpose of this study was to evaluate the therapeutic effect of HA administered by the epidural route on pain induced by foraminal stenosis and to confirm the anti-adhesive and anti-inflammatory properties possibly related to its pain-relieving effect using a rat model of foraminal stenosis.

\section{Materials and methods}

\section{Animal surgery and drugs}

We followed the guide for the care and use of laboratory animals of the National Research Council and the ethical guidelines for animal research by Seoul National University Hospital. This study was approved by the Institutional Animal Care and Use Committees of Seoul National University Hospital (IACUC No. 09-2003-0060).

Male Sprague Dawley rats weighing 200-250 g were used in this study. They had free access to food and water and were housed individually in plastic cages with soft bedding under a 12-h light-dark cycle at a constant temperature of $20-22^{\circ} \mathrm{C}$ and a humidity level of 55-60\%. The animals were acclimatized for at least 1 week before surgery.

The surgical procedure was performed aseptically under general anesthesia with 3\% isoflurane and oxygen. The foraminal stenosis model was developed in accordance with a previously described method ${ }^{19}$ but with some modifications. After the midline incision, the neural foramen of the left $\mathrm{L}_{5}$ was exposed and a stainless steel rod $3 \mathrm{~mm}$ long and 0.6$0.8 \mathrm{~mm}$ wide was inserted into the foramen. Then, an epidural catheterization was performed at $\mathrm{T}_{13}-\mathrm{L}_{1}$ intervertebral space following a previously described method. ${ }^{20}$ A polyethylene tube (PE-10; Natsume Seisakusho Co., Ltd., Tokyo, Japan) was inserted into the epidural space and gently advanced $\sim 3.0 \mathrm{~cm}$ in a caudal direction to place its tip between the $\mathrm{L}_{5}$ and $\mathrm{L}_{6}$ levels. All animals were allowed to recover for 3 days after epidural catheterization.

Following surgery, rats were excluded if blood or CSF was aspirated from the epidural catheter or if postoperative neurologic deficits were identified. The final study population comprised 76 rats. To verify the animal model in the first stage of this study, 10 rats from the foraminal stenosis group and 10 rats from the sham control group were selected. In the sham controls, the neural foramen of left $\mathrm{L}_{5}$ was exposed, but the rod was not inserted and epidural catheterization was not performed. In the second stage, the remaining rats were divided into two groups and received epidural injection of either $0.1 \mathrm{~mL}$ of HA (Hyuran Plus ${ }^{\circledR}$; LG Pharm, Seoul, Korea; HA group, $\mathrm{n}=26$ ) or $0.9 \%$ of saline solution ( $\mathrm{S}$ group, $\mathrm{n}=26$ ) on postoperative day 3 . To assess macroscopic epidural adhesion on the third postoperative day, four additional rats that underwent the same surgery including epidural catheter insertion but without epidural injection were sacrificed. For the macroscopic examination, seven and six rats in each group were sacrificed at 1 and 3 weeks, respectively, after epidural injection. Also for the microscopic examination, seven and six rats in each group were sacrificed at 1 and 3 weeks, respectively, after epidural injection (Figure 1).

\section{Behavioral testing}

All behavioral tests were performed during the daylight ( 9 am to $3 \mathrm{pm}$ ) portion of the regulated circadian cycle by one researcher blinded to study group allocation. The mechanical threshold ${ }^{21,22}$ and motor function ${ }^{23,24}$ were assessed. To measure the mechanical threshold, each rat was placed in an individual plastic cage with a wire mesh bottom. After a 20-min acclimatization period, calibrated von Frey filaments (Stoelting Co., Wood Dale, IL, USA) of logarithmically incremental increasing stiffness $(0.41,0.70,1.20,2.00,3.63,5.50$, 8.50 , and $15.10 \mathrm{~g}$ ) were applied to the mid-plantar surface of the hind paw. The mechanical threshold was assessed using an up-down statistical method. . $^{21,22}$

Motor function was assessed on a four-level scale. ${ }^{24}$ The grades were defined as follows: grade $1=$ normal gait with no foot deformities; grade $2=$ normal gait with a marked foot deformity, including a plantar flexed toe or an inverted foot; grade 3 = slight gait disturbance in which a foot drop 


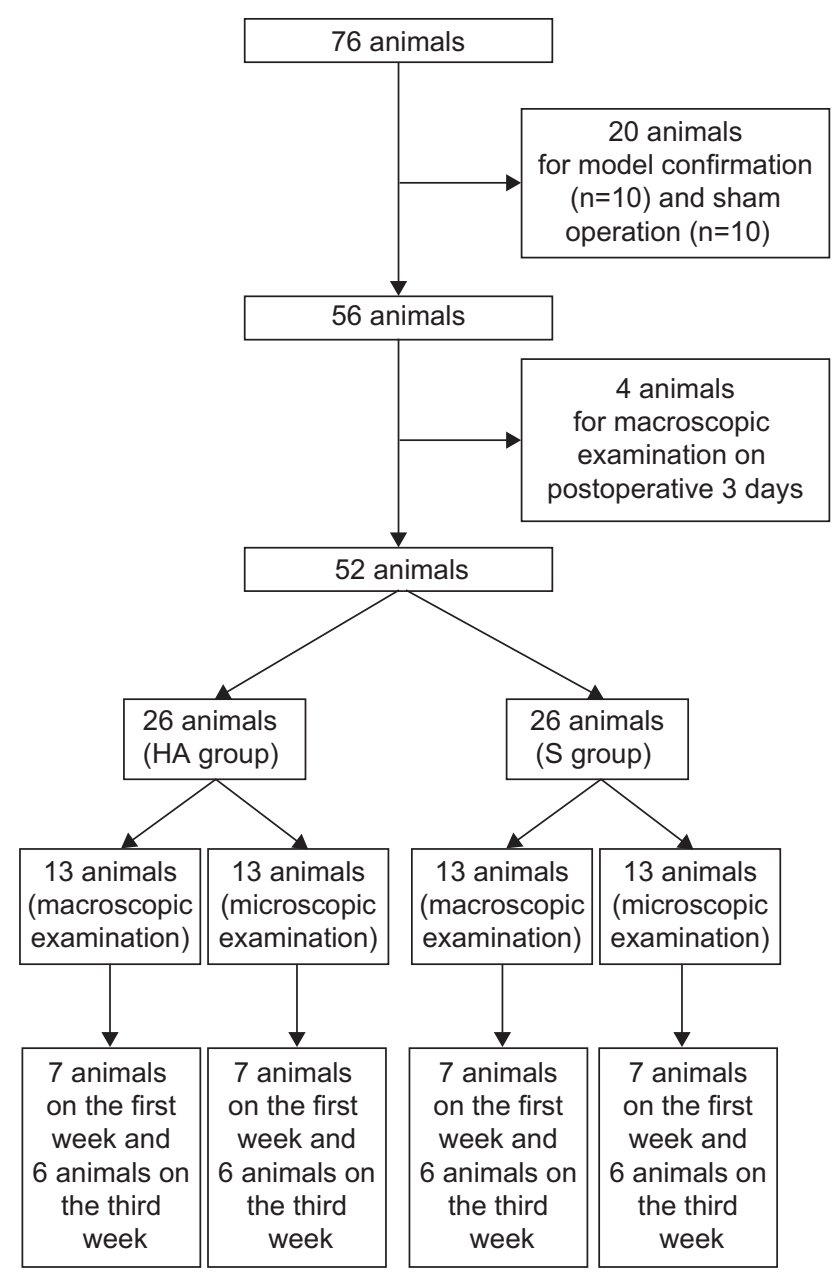

Figure I Flow diagram of the study.

Notes: A total of 76 animals were included. HA group, epidural injection of $0.1 \mathrm{~mL}$ of HA 3 days postoperatively in the rat foraminal stenosis model; $\mathrm{S}$ group, epidural injection of $0.1 \mathrm{~mL}$ of saline solution 3 days postoperatively.

Abbreviations: HA, hyaluronic acid; $S$, saline solution.

was present; and grade $4=$ severe gait disturbance with motor paresis of the ipsilateral hind paw. Motor dysfunction was defined as a grade $>2$. The rats were monitored for behavioral changes, including abnormal posture, lameness, and change in eating habits, as well as signs of agitation during epidural injection, such as convulsions, squealing, and hyperventilation.

Behavioral tests were conducted before surgery, 3 days following surgery before epidural injection of the test solutions, and 1 and $4 \mathrm{~h}$ and 1, 2, 4, 7, 11, 14, and 21 days after the injection.

\section{Histopathologic examination}

Perineural adhesion/fibrosis and inflammation around the left $\mathrm{L}_{5}$ neural foramen were assessed. The animals were anesthetized with $3 \%$ isoflurane and perfused transcardially with saline followed by $4 \%$ paraformaldehyde in $0.1 \mathrm{M}$ phosphate. To examine perineural adhesion/fibrosis macroscopically, the spinal canal from $\mathrm{L}_{4}-\mathrm{L}_{6}$ and the left $\mathrm{L}_{5}$ neural foramen were exposed. Fibrosis/adhesion was evaluated macroscopically by an investigator blinded to group allocation using the classification described by Rydell and Balazs ${ }^{25}$ (grade $0=$ no significant adhesions; grade $1=$ thin, sparse, and easily broken adhesions; grade $2=$ dense adhesions that can be disrupted with dissection; and grade $3=$ adhesions so dense that they have to be cut with a knife.

For microscopic examination of the degree of fibrosis, inflammation, and segmental chromatolysis, the vertebral columns from $\mathrm{L}_{4}-\mathrm{L}_{6}$, including the dorsal root ganglion (DRG), nerve root, and spinal nerve of $\mathrm{L}_{5}$, were cropped en bloc and the overlying muscles were removed. The sample was post-fixed in a $10 \%$ buffered formalin solution for $48 \mathrm{~h}$ and then decalcified with $10 \% \mathrm{w} / \mathrm{v}$ ethylenediaminetetraacetic acid and embedded in a paraffin block. The slides were prepared from $4-\mu \mathrm{m}$ sections and stained with hematoxylin and eosin. Masson's trichrome stains were also performed to evaluate the degree of perineural fibrosis. A blinded pathologist (GYC) assessed the histologic degree of fibrosis, inflammation, and segmental chromatolysis. The degree of fibrosis around the left $\mathrm{L}_{5}$ DRG was assessed according to two histologic parameters, that is, character of fibrosis (loose vs dense) and extent of fibrosis (focal vs diffuse). Perineural fibrosis was evaluated on a 5 -grade scale (grade $0=$ absence of fibrosis, grade $1=$ loose or focal fibrosis, grade $2=$ loose or diffuse fibrosis [ $>50 \%$, grade $3=$ dense or focal fibrosis, and grade $4=$ dense or diffuse fibrosis [ $>50 \%$ ]; Figure 2 ).

The degree of inflammation was evaluated based on the grading system developed by Salafia et $\mathrm{al}^{26}$ with minor modifications. Neither the HA group nor the S group showed any neutrophilic infiltration. Therefore, there was no evidence of acute suppurative inflammation. Chronic inflammation was assessed in the area where the most mononuclear inflammatory cells (lymphocytes, histiocytes, and plasma cells) were infiltrated. The degree of chronic inflammation was graded as follows: grade $0=$ absent, grade $1=$ one focus of at least five mononuclear inflammatory cells, grade $2=$ more than one focus of grade 1 or at least one focus of 5-20 mononuclear inflammatory cells, grade $3=$ multiple confluent foci of grade 2 , and grade $4=$ diffuse and dense inflammation. ${ }^{26}$ For evaluation of segmental chromatolysis, the number of ganglion cells with segmental chromatolysis was counted. The percentage of ganglion cells with segmental chromatosis among all the ganglion cells in the DRG were compared between the two groups. Figure 3 shows the ganglion cells with segmental chromatolysis. 
A

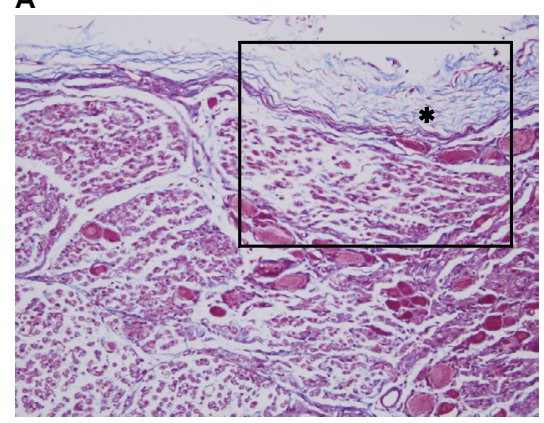

C

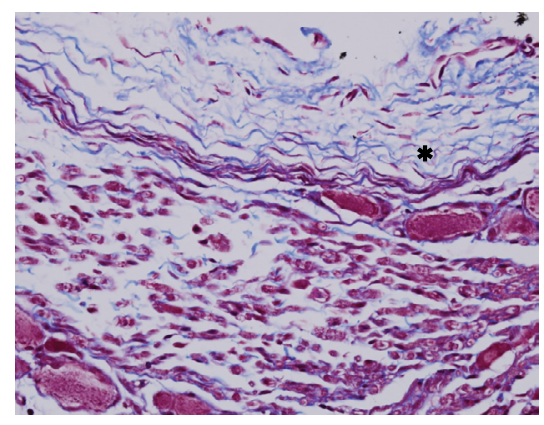

B

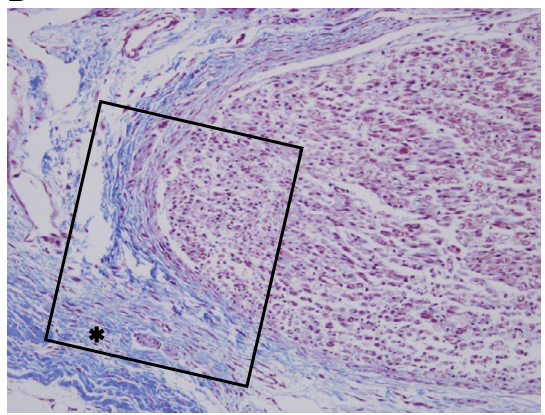

D

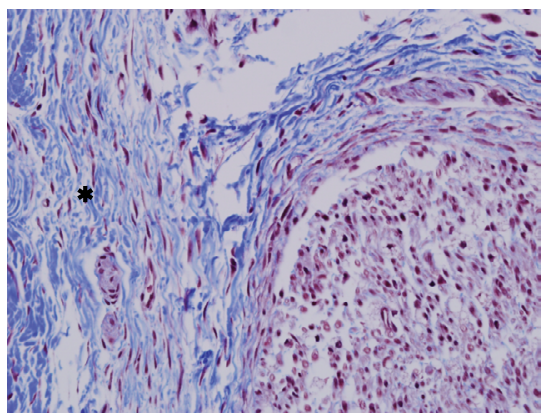

Figure 2 Microscopic evaluation of perineural fibrosis at the left dorsal root ganglia.

Notes: (A) Focal loose fibrosis (grade I; MT, $\times 200$ ). (B) Diffuse dense fibrosis (grade 4; MT, $\times 200$ ). (C) High-power view of the box in A (MT, $\times 400)$. (D) High-power view of the box in B (MT, $\times 400)$. Fibrotic regions appear in blue upon MT staining (asterisks).

Abbreviation: MT, Masson's trichrome.

A

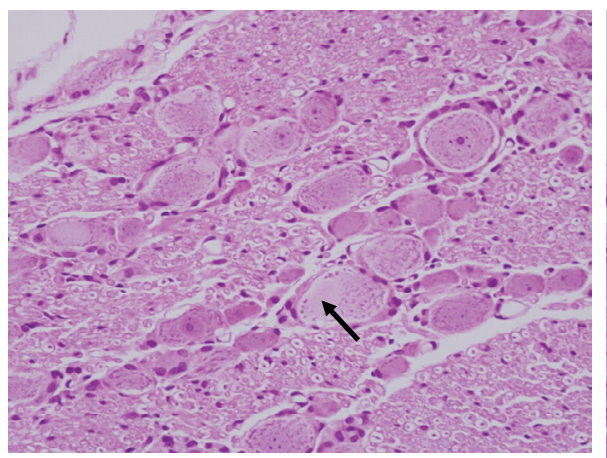

B

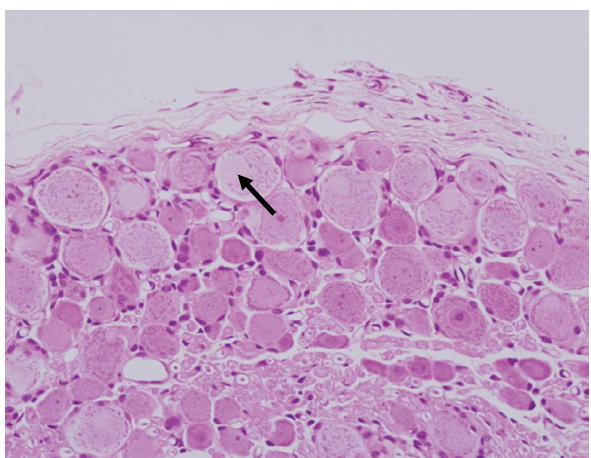

Figure 3 Microscopic findings for the left dorsal root ganglia I week after epidural injection.

Notes: The arrows indicate segmental chromatolysis. (A) H\&E staining, $\times I, 000$. (B) H\&E staining, $\times 400$.

Abbreviation: H\&E, hematoxylin and eosin.

\section{Statistical analysis}

Data are reported as mean \pm standard error of the mean (SEM). The paw-withdrawal threshold was compared within each treatment group using repeated measures analysis of variance, followed by a multiple comparison with Bonferroni correction. Comparisons between the two groups at each time point were determined using the Wilcoxon rank-sum test. The degrees of perineural adhesion, fibrosis, and inflammation were analyzed using Fisher's exact test. The percentage of ganglion cells with segmental chromatolysis were analyzed using Wilcoxon rank-sum test. $P$-values $<0.05$ were considered to be statistically significant.

\section{Results}

\section{Behavioral testing}

All rats showed normal gait, normal feeding, and regular weight gain within $1 \mathrm{~h}$ after surgery. We observed no signs of agitation during epidural injection or any associated behavioral changes.

The stainless steel rod inserted into the $\mathrm{L}_{5}$ neural foramen produced a significant decrease in the withdrawal threshold post-surgery and remained stable for 21 days. The sham surgery caused no significant changes in the withdrawal threshold compared with pre-surgical values (Figure 4). 


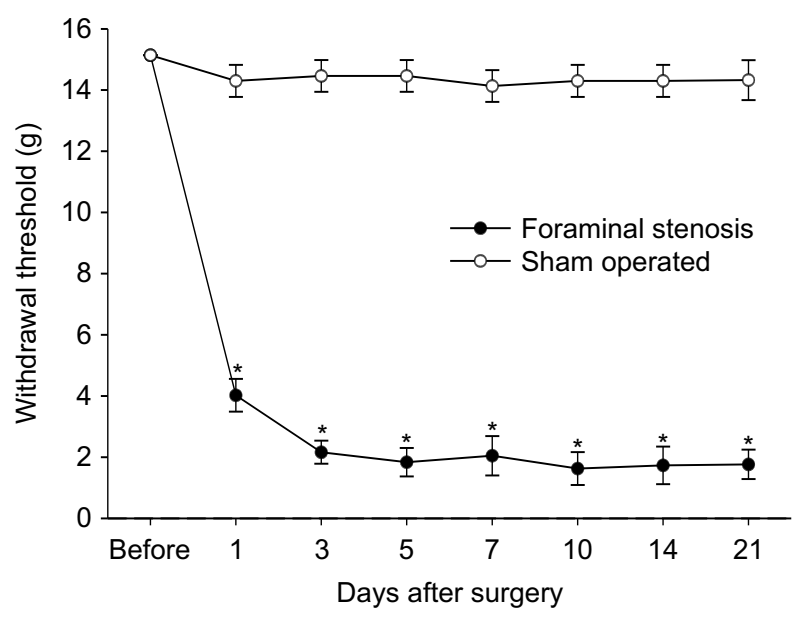

Figure $4 \mathrm{~A}$ stainless steel rod inserted into the L5 neural foramen significantly reduced the paw-withdrawal threshold on the plantar surface of the ipsilateral hind paw.

Notes: Each point represents the mean \pm SEM ( $n=10$ per group). $* P<0.05$ versus the sham control.

Abbreviation: SEM, standard error of the mean.

Significantly more alleviation of hypersensitivity was seen in the HA group than in the S group at $4 \mathrm{~h}$ after the epidural injection $(P<0.001)$. This increased paw-withdrawal threshold remained for 3 weeks after the injection (Figure 5).

\section{Histopathologic examination}

On macroscopic examination, all four rats that underwent surgery including epidural catheterization without epidural injection showed grade 1 adhesion around the left $\mathrm{L}_{5}$ DRG

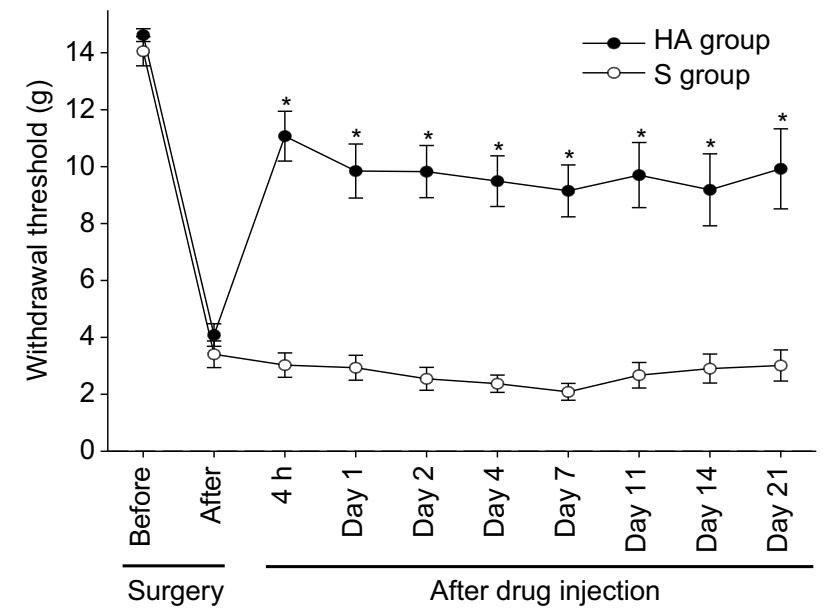

Figure 5 Changes to the withdrawal threshold in the hyaluronic acid (HA) group and saline (S) group.

Notes: Each point represents the mean \pm SEM change in the 26 rats per group from before surgery (indicated as "before") to I week after epidural injection of the test solutions (day 7); these figures are presented for 13 rats per group for the period thereafter. $* P<0.05$ versus the $S$ group. HA group, epidural injection of $0.1 \mathrm{~mL}$ of HA 3 days postoperatively in the rat foraminal stenosis model; S group, epidural injection of $0.1 \mathrm{~mL}$ of saline solution 3 days postoperatively.

Abbreviation: SEM, standard error of the mean.
Table I Macroscopic evaluation of perineural adhesions after injecting an epidural hyaluronic acid (HA) or saline solution (S)

\begin{tabular}{|c|c|c|c|c|c|}
\hline \multirow[t]{3}{*}{$\overline{\text { Grade }}$} & \multirow{3}{*}{$\begin{array}{l}\text { Three days } \\
\text { post surgery } \\
\text { (no epidural } \\
\text { injection, } \\
n=4 \text { ) }\end{array}$} & \multicolumn{4}{|c|}{ Time after epidural injection } \\
\hline & & \multicolumn{2}{|l|}{ I week } & \multicolumn{2}{|l|}{3 weeks } \\
\hline & & $\begin{array}{l}\text { HA group* } \\
(n=10)\end{array}$ & $\begin{array}{l}\text { S group } \\
(n=10)\end{array}$ & $\begin{array}{l}\text { HA group } \\
(n=10)\end{array}$ & $\begin{array}{l}\text { S group } \\
(n=10)\end{array}$ \\
\hline 0 & 0 & 0 & 0 & 0 & 0 \\
\hline 1 & 4 & 2 & 0 & 1 & 0 \\
\hline 2 & 0 & 5 & I & 3 & I \\
\hline 3 & 0 & 3 & 9 & 6 & 9 \\
\hline
\end{tabular}

Notes: Grade 0 = no significant adhesions; grade I = thin, sparse, and easily broken adhesions; grade 2 = dense adhesions that could be disrupted with dissection; and grade $3=$ adhesions so dense that they had to be cut with knife. $* P<0.05$ versus the corresponding S group. HA group, epidural injection of $0.1 \mathrm{~mL}$ of HA 3 days postoperatively in the rat foraminal stenosis model; $\mathrm{S}$ group, epidural injection of $0.1 \mathrm{~mL}$ of saline solution 3 days postoperatively.

Table 2 Microscopic perineural fibrosis evaluation

\begin{tabular}{|c|c|c|c|c|}
\hline \multirow[t]{3}{*}{ Grade } & \multicolumn{4}{|c|}{ Time after epidural injection } \\
\hline & \multicolumn{2}{|l|}{ I week } & \multicolumn{2}{|l|}{3 weeks } \\
\hline & $\begin{array}{l}\text { HA group* } \\
(n=7)\end{array}$ & $\begin{array}{l}\text { S group } \\
(n=7)\end{array}$ & $\begin{array}{l}\text { HA group* } \\
(n=6)\end{array}$ & $\begin{array}{l}\text { S group } \\
(n=6)\end{array}$ \\
\hline 0 & 1 & 0 & 0 & 0 \\
\hline I & 5 & I & 4 & 0 \\
\hline 2 & I & 1 & 2 & 4 \\
\hline 3 & 0 & 3 & 0 & I \\
\hline 4 & 0 & 2 & 0 & 1 \\
\hline
\end{tabular}

Notes: Perineural fibrosis was evaluated as grade $0=$ absent; grade $1=$ loose and focal fibrosis; grade 2 = loose and diffuse fibrosis, $>50 \%$; grade $3=$ dense and focal fibrosis; and grade $4=$ dense and diffuse fibrosis, $>50 \%$. $* P<0.05$ versus the corresponding S group. HA group, epidural injection of $0.1 \mathrm{~mL}$ of HA 3 days postoperatively in the rat foraminal stenosis model; $\mathrm{S}$ group, epidural injection of $0.1 \mathrm{~mL}$ of saline solution 3 days postoperatively.

Abbreviations: HA, hyaluronic acid; S, saline solution.

on postoperative day 3 immediately before the epidural injection. One week after the injection, the perineural adhesion had decreased significantly in the HA group $(P=0.025)$. However, we found no significant difference in the degree of adhesion between the groups 3 weeks after the injection ( $P=0.303$; Table 1).

On microscopic examination, perineural fibrosis decreased more in the HA group than in the $\mathrm{S}$ group after 1 week $(P=0.026)$. After 3 weeks, the degree of fibrosis was less in the HA group, but not significantly so $(P=0.061$; Table 2). Microscopic evaluation showed no statistically significant difference in the degree of chronic inflammation between the HA group and the S group (Table 3).

We found a significantly lower percentage of segmental chromatosis in ganglion cells in the HA group than in the $S$ group after 1 week $(P=0.002$; Figure 6$)$; however, the difference was not statistically significant after 3 weeks $(P=0.082)$. 
Table 3 Microscopic evaluation of chronic inflammation

\begin{tabular}{|c|c|c|c|c|}
\hline \multirow[t]{3}{*}{ Grade } & \multicolumn{4}{|c|}{ Time after epidural injection } \\
\hline & \multicolumn{2}{|l|}{ I week } & \multicolumn{2}{|l|}{3 weeks } \\
\hline & $\begin{array}{l}\text { HA group } \\
(n=7)\end{array}$ & $\begin{array}{l}\text { S group } \\
(n=7)\end{array}$ & $\begin{array}{l}\text { HA group } \\
(n=6)\end{array}$ & $\begin{array}{l}\text { S group } \\
(n=6)\end{array}$ \\
\hline 0 & I & 0 & 0 & 0 \\
\hline $\mathrm{I}$ & 3 & 2 & 4 & 3 \\
\hline 2 & 3 & 4 & 2 & 2 \\
\hline 3 & 0 & I & 0 & 1 \\
\hline 4 & 0 & 0 & 0 & 0 \\
\hline
\end{tabular}

Notes: Grade 0 = absent, grade I = one focus of at least five cells, grade 2 = more than one focus of grade $I$ or at least one focus of 5-20 cells, grade $3=$ multiple confluent foci of grade 2 , and grade $4=$ diffuse and dense inflammation. We found no significant differences between the groups. HA group, epidural injection of $0.1 \mathrm{~mL}$ of HA 3 days postoperatively in the rat foraminal stenosis model; $\mathrm{S}$ group, epidural injection of $0.1 \mathrm{~mL}$ of saline solution 3 days postoperatively.

Abbreviations: $\mathrm{HA}$, hyaluronic acid; $\mathrm{S}$, saline solution.

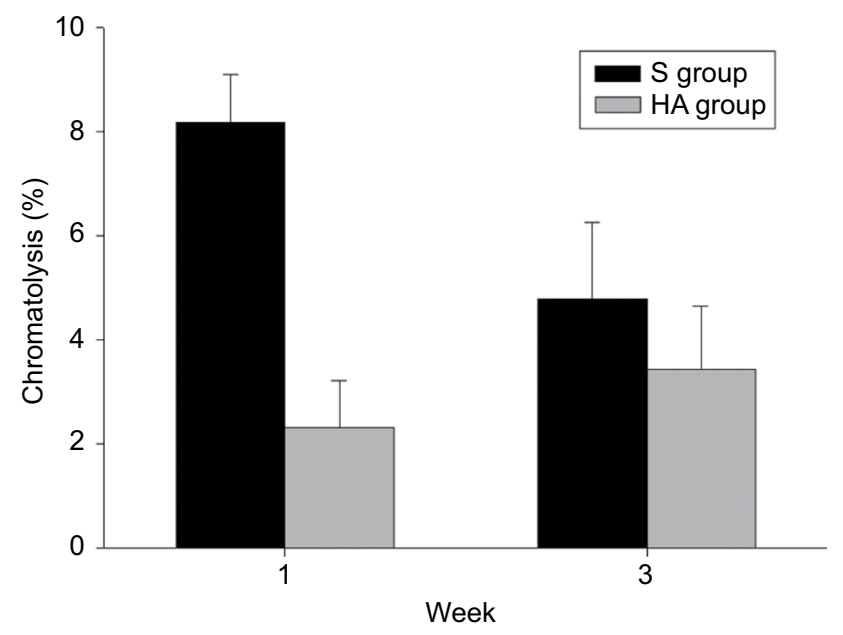

Figure 6 Percentage of segmental chromatosis in the ganglion cells in the left dorsal root ganglia I and 3 weeks after epidural injection of saline solution (S) or hyaluronic acid (HA)

Notes: The HA group had significantly fewer chromatolytic cells than the $\mathrm{S}$ group at I week $(P=0.002)$. S group, epidural injection of $0.1 \mathrm{~mL}$ of saline solution 3 days postoperatively; HA group, epidural injection of $0.1 \mathrm{~mL}$ of $\mathrm{HA} 3$ days postoperatively in the rat model of foraminal stenosis.

\section{Discussion}

In this study, epidural administration of HA restored the decreased mechanical pain thresholds significantly. Therefore, we suggest that HA has a therapeutic effect on the allodynia or hyperalgesia induced by chronic compression of the DRG.

This study used the animal model of chronic steady compression of the DRG introduced by $\mathrm{Hu}$ and Xing. ${ }^{19}$ Chronic compression of the DRG can produce intraneural edema and reduce blood flow to the somata of sensory nerve cells, causing a change in neuronal excitability, ${ }^{27}$ thereby producing hyperalgesia to mechanical stimulation of the ganglioninjured hind paw. ${ }^{28}$ In this study, all rats exhibited decreased mechanical and thermal thresholds post surgery. Thus, this model reflects the effects of HA on the sensory pathology caused by chronic compression of the DRG.
Epidural adhesion following spine surgery is a major cause of radiating pain with or without low back pain, ${ }^{29}$ and much effort has been made to reduce epidural fibrosis. In this study, the degree of epidural fibrosis was significantly lower in the HA group than in the $\mathrm{S}$ group on macroscopic and microscopic examinations; these findings are consistent with the results of Songer et al, ${ }^{30}$ who reported that epidural HA prevented development of epidural fibrosis after spine surgery in dogs. The antifibrotic effect of HA may be related to restoration of the mechanical threshold.

Inflammatory cells, such as macrophages, have been found to be present in the DRG after peripheral axotomy. ${ }^{31}$ Some inflammatory mediators, including bradykinin, prostaglandin, and serotonin, enhance normal and injured sensory neuronal excitability, suggesting that inflammation is critical for generating neural sensitization. ${ }^{23}$ In this study, inflammatory cells were found around the DRG, suggesting that the rod inserted into the $\mathrm{L}_{5}$ neural foramen caused irritation and inflammation around the DRG. Therefore, chronic compression and secondary inflammation of the DRG may help to generate the hyperexcitability of DRG neurons. Conversely, we observed no significant difference between the experimental groups in terms of chronic inflammation. Microscopic differences in perineural fibrosis could have compensated for these results. The results of this study demonstrate that HA participated in tissue repair and wound healing. Tissue repair involves two processes, that is, regeneration and replacement by connective tissue, known as fibrosis. Although we found no statistically significant difference in inflammation in this study, the smaller change in fibrosis in the HA group does indicate an anti-inflammatory effect.

Similarly, segmental chromatosis of ganglion cells, which indicates segmental (not global) disintegration of nuclear chromatin, is evidence of chronic compression and continuous damage of the DRG. ${ }^{32}$ Therefore, the smaller percentage of segmental chromatolysis in the HA group when compared with the $\mathrm{S}$ group indicates that HA had a protective effect on DRG injury and neural regeneration. This effect may be important in restoring the decreased mechanical thresholds induced by foraminal stenosis.

In our study, the degree of perineural fibrosis on histopathologic examination showed a significant difference between the groups at 1 week, but the difference had disappeared by 3 weeks. Because only one epidural injection was performed, it is unclear whether repeated epidural injections would have led to further improvement in histopathologic findings. Further investigation is needed on the long-term effect of HA injection into the epidural space, as well as the effect of repeated injections. 


\section{Conclusion}

Epidural administration of HA restored the mechanical threshold induced by foraminal stenosis in rats. The lubricating, osmotic, and neural regeneration effects of HA may also have contributed to restoration of mechanical stimulation. Our results suggest that epidural HA effectively reduces the pain related to perineural adhesion. Furthermore, HA may be useful in interventional pain management, including epiduroscopic adhesiolysis and selective transforaminal injection, by minimizing readhesion and inflammatory changes.

\section{Disclosure}

The authors report no conflicts of interest in this work.

\section{References}

1. Kim EJ, Moon JY, Park KS, et al. Epidural steroid injection in Korean pain physicians: a national survey. Korean J Pain. 2014;27(1):35-42.

2. Gupta S, Gupta M, Nath S, Hess GM. Survey of European pain medicine practice. Pain Physician. 2012;15(6):E983-E994.

3. Benyamin RM, Manchikanti L, Parr AT, et al. The effectiveness of lumbar interlaminar epidural injections in managing chronic low back and lower extremity pain. Pain Physician. 2012;15(4):E363-E404.

4. US Food Drug Administration [webpage on the Internet]. FDA Drug Safety Communication: FDA Requires Label Changes to Warn of Rare but Serious Neurologic Problems after Epidural Corticosteroid Injections for Pain. 2014. Available from: http://www.fda.gov/Drugs/ DrugSafety/ucm394280.htm. Accessed September 1, 2016.

5. Manchikanti L, Candido K, Singh V, et al. Epidural steroid warning controversy still dogging FDA. Pain Physician. 2014;17(4):E451-E474.

6. Saito S, Furuya T, Kotake S. Therapeutic effects of hyaluronate injections in patients with chronic painful shoulder: a meta-analysis of randomized controlled trials. Arthritis Care Res (Hoboken). 2010;62(7): 1009-1018.

7. Saito S, Kotake S. Is there evidence in support of the use of intraarticular hyaluronate in treating rheumatoid arthritis of the knee? A meta-analysis of the published literature. Mod Rheumatol. 2009;19(5): 493-501.

8. Friedman PM, Mafong EA, Kauvar AN, Geronemus RG. Safety data of injectable nonanimal stabilized hyaluronic acid gel for soft tissue augmentation. Dermatol Surg. 2002;28(6):491-494.

9. Voigt J, Driver VR. Hyaluronic acid derivatives and their healing effect on burns, epithelial surgical wounds, and chronic wounds: a systematic review and meta-analysis of randomized controlled trials. Wound Repair Regen. 2012;20(3):317-331.

10. Zeng Q, Yu Z, You J, Zhang Q. Efficacy and safety of Seprafilm for preventing postoperative abdominal adhesion: systematic review and meta-analysis. World J Surg. 2007;31(11):2125-2131.

11. Schimizzi AL, Massie JB, Murphy M, et al. High-molecular-weight hyaluronan inhibits macrophage proliferation and cytokine release in the early wound of a preclinical postlaminectomy rat model. Spine J. 2006;6(5):550-556.

12. Ozgenel GY. Effects of hyaluronic acid on peripheral nerve scarring and regeneration in rats. Microsurgery. 2003;23(6):575-581.

13. Takeshima N, Miyakawa H, Okuda K, et al. Evaluation of the therapeutic results of epiduroscopic adhesiolysis for failed back surgery syndrome. Br J Anaesth. 2009;102(3):400-407.
14. Richards PJ, Turner AS, Gisler SM, et al. Reduction in postlaminectomy epidural adhesions in sheep using a fibrin sealant-based medicated adhesion barrier. J Biomed Mater Res B Appl Biomater. 2010;92(2):439-446.

15. Wu CY, Huang YH, Lee JS, Tai TW, Wu PT, Jou I. Efficacy of topical cross-linked hyaluronic acid hydrogel in preventing post laminectomy/ laminotomy fibrosis in a rat model. J Orthop Res. 2016;34(2):299-306.

16. Songer MN, Rauschning W, Carson EW, Pandit SM. Analysis of peridural scar formation and its prevention after lumbar laminotomy and discectomy in dogs. Spine. 1995;20(5):571-578.

17. Massie JB, Schimizzi AL, Huang B, Kim CW, Garfin SR, Akeson WH. Topical high molecular weight hyaluronan reduces radicular pain post laminectomy in a rat model. Spine J. 2005;5(5):494-502.

18. Sakayama K, Kidani T, Sugawara Y, Masuno H, Matsuda Y, Yamamoto H. Elevated concentration of hyaluronan in the cerebrospinal fluid is a secondary marker of spinal disorders: hyaluronan in the cerebrospinal fluid in patients with spinal disorders. J Spinal Disord Tech. 2006; 19(4):262-265.

19. Hu SJ, Xing JL. An experimental model for chronic compression of dorsal root ganglion produced by intervertebral foramen stenosis in the rat. Pain. 1998;77(1):15-23.

20. Choi SS, Kim YC, Lim YJ, et al. The neurological safety of epidural gabapentin in rats: a light microscopic examination. Anesth Analg. 2005; 101(5):1422-1426.

21. Dixon WJ. Efficient analysis of experimental observations. Annu Rev Pharmacol Toxicol. 1980;20:441-462.

22. Chaplan SR, Bach FW, Pogrel JW, Chung JM, Yaksh TL. Quantitative assessment of tactile allodynia in the rat paw. JNeurosci Methods. 1994; 53(1):55-63.

23. Kawakami M, Matsumoto T, Hashizume H, Kuribayashi K, Tamaki T. Epidural injection of cyclooxygenase-2 inhibitor attenuates pain-related behavior following application of nucleus pulposus to the nerve root in the rat. J Orthop Res. 2002;20(2):376-381.

24. Kawakami M, Weinstein JN, Spratt KF, et al. Experimental lumbar radiculopathy. Immunohistochemical and quantitative demonstrations of pain induced by lumbar nerve root irritation of the rat. Spine (Phila Pa 1976). 1994;19(16):1780-1794.

25. Rydell N, Balazs EA. Effect of intra-articular injection of hyaluronic acid on the clinical symptoms of osteoarthritis and on granulation tissue formation. Clin Orthop Relat Res. 1971;80:25-32.

26. Salafia CM, Weigl C, Silberman L. The prevalence and distribution of acute placental inflammation in uncomplicated term pregnancies. Obstet Gynecol. 1989;73(3 pt 1):383-389.

27. Rydevik BL, Myers RR, Powell HC. Pressure increase in the dorsal root ganglion following mechanical compression. Closed compartment syndrome in nerve roots. Spine (Phila Pa 1976). 1989;14(6):574-576.

28. Song XJ, Hu SJ, Greenquist KW, Zhang JM, LaMotte RH. Mechanical and thermal hyperalgesia and ectopic neuronal discharge after chronic compression of dorsal root ganglia. J Neurophysiol. 1999; 82(6):3347-3358.

29. Ross JS, Robertson JT, Frederickson RC, et al. Association between peridural scar and recurrent radicular pain after lumbar discectomy: magnetic resonance evaluation. ADCON-L European Study Group. Neurosurgery. 1996;38(4):855-861.

30. Songer MN, Ghosh L, Spencer DL. Effects of sodium hyaluronate on peridural fibrosis after lumbar laminotomy and discectomy. Spine. 1990;15(6):550-554.

31. Song XJ, Zhang JM, Hu SJ, LaMotte RH. Somata of nerve-injured sensory neurons exhibit enhanced responses to inflammatory mediators. Pain. 2003;104(3):701-709.

32. Safonova GD, Kovalenko AP. Morphofunctional characteristics of neurons in the spinal ganglia of the dog in the post-distraction period. Neurosci Behav Physiol. 2006;36(5):491-494. 
The Journal of Pain Research is an international, peer reviewed, open access, online journal that welcomes laboratory and clinical findings in the fields of pain research and the prevention and management of pain. Original research, reviews, symposium reports, hypothesis formation and commentaries are all considered for publication.
The manuscript management system is completely online and includes a very quick and fair peer-review system, which is all easy to use. Visit http://www.dovepress.com/testimonials.php to read real quotes from published authors.

Submit your manuscript here: https://www.dovepress.com/journal-of-pain-research-journal 